\title{
ANALYSIS OF GRAMMATICAL COHESION TOOLS IN STUDENTS ESSAY AT INDRAPRASTA PGRI UNIVERSITY
}

\author{
Reni Rokhayati* \\ Universitas Indraprasta PGRI \\ Ila Nafilah \\ Universitas Indraprasta PGRI \\ Arinah Fransori \\ Universitas Indraprasta PGRI
} Jl. Raya Tengah No. 80, Kel. Gedong, Kec. Pasar Rebo, Jakarta Timur 13760; Indonesia
e-mail: lenirokhayati@gmail.com

\begin{abstract}
The purpose of this study is to analyze and describe or obtain a clear picture of grammatical cohesion consisting of references, substitutions, ellipsis, and conjunctions in the essays of Indraprasta PGRI University students. This study used descriptive qualitative method. In this study the fact of language is in the form of discourses in essays with a focus on the study of grammatical cohesion analysis. The methode used in this researched inquired methode with notestaken technique, which mean the researcher recorded the data that was considered appropriate in the study of cohesion analysis and discourse coherence in student essays. The technique used is to analyze based on one-to-one relationships with other sentences in the essay. The data source used is a student essay in the Literature Psychology course, there are 30 student essays taken as research data. The results of this study indicate that the grammatical cohesile device is; reference 46 with a percentage of $24.1 \%$, substitution 5 with a percentage of $2.6 \%$, ellipsis 8 with a percentage of $4.2 \%$ and conjunctive relations 132 with a percentage of $69.1 \%$. Based on this, from 30 essays written by students there are 191 numbers of grammatical cohesion tools used.
\end{abstract}

Key Words: student essay, tool for grammatical cohesion, conjungsion

\begin{abstract}
Article History: Received: 23/09/2019; Revised: 24/10/2019; Accepted: 27/11/2019; Published: 31/12/2019
How to Cite (MLA $7^{\text {th): }}$ Rokhayati, Reni dan Fransori, Arinah. "Analysis of Grammatical Cohesion Tools in Students Essay at Indraprasta PGRI University." Hortatori Jurnal Pendidikan Bahasa dan Sastra Indonesia 3.02 (2019): 125132. Print/Online. Copyrights Holder: Rokhayati, Reni dan Fransori, Arinah. First Publication: Hortatori Jurnal Pendidikan Bahasa dan Sastra Indonesia (2019).
\end{abstract}

\section{Pendahuluan}

Bahasa merupakan alat komunikasi yang penting bagi manusia. Tanpa bahasa manusia tidak mungkin dapat berkomunikasi. Dengan bahasa, manusia dapat menyampaikan berbagai berita, pikiran, pengalaman, gagasan, pendapat, perasaan, dan lain-lain kepada orang lain. Bahasa meliputi tataran fonologi, morfologi, sintaksis, semantik, dan wacana (Zaenal Arifin, 2012:1)

Sebagai objek kajian dalam ilmu kebahasaan, wacana dapat ditelusuri dari berbagai segi. Selain itu, aspek-aspek yang terkandung di dalamnya menyajikan jenis kajian yang sangat beragam. Kohesi merupakan salah satu bagian dalam kajian wacana. Kohesi terdiri dari kohesi leksikal dan kohesi gramatikal.

Pendidikan merupakan tempat terjadinya proses belajar mengajar yang direncanakan untuk 
mengembangkan bakat dan potensi siswa. Salah satu hal yang tidak dapat terpisahkan dalam proses pembelajaran yaitu menulis, sebab menulis berarti melatih siswa agar mempunyai kemampuan untuk berpikir kritis. Menulis atau membuat Esai tidaklah mudah sehingga diperlukan latihan yang kontinyu. Permasalahan dalam menulis atau membuat karangan muncul jika Mahasiswa menemukan kesulitan dalam menentukan topik dan kurangnya atau minimnya pengetahuan dalam menuangkan ide, gagasan dan pikiran secara sistematis dan logis.

Latar belakang penelitian ini adalah masih ditemukannya ketidakpaduan atau ketidakselarasan esai yang dibuat oleh mahasiswa program studi pendidikan bahasa Indonesia pada mata kuliah Psikologi Sastra. Hal ini dapat dilihat dari kurang cermatnya kohesi atau bentuk dalam paragraf yang dibuat oleh mahasiswa tersebut. Berdasarkan esai mahasiswa yang diperoleh langsung dari pengajaran mata kuliah Psikologi Sastra, masih banyak ditemukan kesalahan-kesalahan dalam esai mahasiswa khususnya dari segi kohesi gramatikal. Rumusan masalah dalam penelitian ini bagaimanakah piranti kohesi gramatikal dalam esai mahasiswa Universitas Indraprasta PGRI ?

Bertitik dari rumusan masalah tersebut, tim peneliti berupaya menganalisis dan mendeskripsikan atau memperoleh gambaran yang jelas mengenai kohesi gramatikal yang terdiri dari referensi, subtitusi, ellipsis, dan konjungsi. Penelitian ini diharapkan dapat menambah wawasan mengenai kesalahan gramatikal yang dibuat mahasiswa. Berdasarkan latar belakang masalah yang telah dikemukakan di atas, tim peneliti tertarik untuk menganalisis kohesi gramatikal pada esai mahasiswa pada mata kuliah Psikologi Sastra.

Eriyanto (2001: 9) menyatakan wacana adalah menggambarkan teks dan konteks secara bersamasama dalam suatu proses komunikasi. Eriyanto juga berpendapat tentang pentingnya unsur-unsur wacana yaitu konteks, partisipan, interteks, dan situasi. Wacana adalah bentuk praktik sosial, sebagai bentuk dari penerapan hubungan dialek antara kejadian yang nyata dan institusi dengan struktur sosial yang terjadi.

Tarigan (2009:24) mengemukakan adanya delapan unsur-unsur penting dalam wacana, di antaranya: 1) satuan bahasa; 2) terlengkap dan terbesar/tertinggi; 3) di atas kalimat/klausa; 4) teratur/rapi/rasa koherensi; 5) berkesinambungan/kontinuitas 5) rasa kohesi/rasa kepaduan; 6) lisan dan tulis, serta; 7) awal dan akhir yang nyata.

Kohesi adalah keserasian hubungan antara unsur-unsur yang satu dengan unsur yang lain dalam wacana sehingga tercipta pengertian yang baik (koheren). Kalimat atau kata yang dipakai bertautan dan saling mendukung makan. Pengertian yang satu menyambung pengertian yang lainnya sehingga berturut-turut. Dengan demikan ada wacana yang kohesif, koheren dan ada wacana yang tidak kohesif dan koheren (Djajasudarma, 2006: 47).

Gutwinsky (dalam Tarigan, 2009: 93) menyatakan bahwa kohesi adalah hubungan antarkalimat di dalam sebuah wacana, baik dalam skala gramatikal maupun skala leksikal tertentu. Pengetahuan strata dan penguasaan kohesi yang baik memudahkan pemahaman tentang wacana. Wacana benar-benar bersifat kohesif apabila terdapat kesesuaian secara bentuk bahasa terhadap koteks (situasi dalam bahasa; sebagai lawan dari konteks atau situasi luar bahasa).

Esai diartikan sebagai sebuah karangan singkat yang berisi argumen atau pendapat seorang penulis mengenai suatu topik. Penulis biasanya mengemukakan pendapat terhadap suatu persoalan, fenomena atau gejala tertentu yang terjadi di masyarakat. Penulis esai di sebut juga esais, yang juga mengupas topik atau permasalahan tertentu dan memberikan pendapatnya atas topik atau masalah yang dibahasnya (Khuzaemah \& Herawati, 2017).

Esai biasaya disusun berdasarkan tahapan, di mulai dengan paragraf pembuka, paragraf isi atau pengembang dan terakhir paragraf. Sesuai dengan pendapat (Helaluddin, 2017) Pada dasarnya sebuah esai memiliki tiga bagian utama, yaitu: paragraf pembuka (introductory paragraph), beberapa paragraf pengembang (tubuh esai), dan paragraf penutup (cencluding paragraph). Kesemua paragraf tersebut membentuk satu-kesatuan yang saling berkaitan dalam memaparkan suatu topik. Bagian awal adalah paragraf pembuka yang hanya terdiri atas satu paragraf. Pada paragraf pembuka ini penulis memberikan beberapa gambaran umum tentang topik/tema yang akan dibahas. Pada bagian kedua, penulis menjabarkan poin-poin penting yang menjadi isu dalam esai tersebut. Banyaknya paragraf pada tubuh esai ini tentu saja tergantung pada banyaknya poin yang tercantum pada pernyataan tesis di paragraf pembuka. Selanjutnya, penulis menutup esai dengan sebuah paragraf penutup. 


\section{Metode}

Penelitian ini menggunakan metode deskriptif kualitatif. Dalam penelitian ini fakta bahasa berupa wacana-wacana dalam esai dengan fokus kajian analisis kohesi gramatikal. Pendekatan kualitatif yang digunakan dalam penelitian ini sebagai prosedur dalam memecahkan masalah yang sedang diteliti dengan cara mendeskripsikan atau menggambarkan masalah. Deskripsi masalah terhadap objek penelitian yang dipilih didasarkan pada fakta-fakta apa adanya. Pendekatan ini digunakan dengan maksud untuk memecahkan masalah yang sedang dihadapi Metode yang digunakan dalam penelitian ini metode inkuiri dengan teknik catat, yang berarti peneliti mencatat data yang dinilai tepat dalam kajian analisis kohesi dan koherensi wacana pada esai mahasiswa. Kedua dengan pencatatan dilakukan setelah data yang berupa wacana-wacana esai tersebut dinilai cukup untuk dijadikan data penelitian. Data kemudian dicatat dalam kartu data untuk dianalisis mengenai kohesi gramatikal yang digunakan untuk menciptakan kesinambungan.

Peneliti menggunakan teknik analisis isi. Yaitu menganalisis keseluruhan kalimat di dalam esai mahasiswa. Dalam penelitian ini menggunakan konteks yang bersifat intralinguistik atau dengan kata lain pertalian makna antarkalimat diungkap berdasarkan hubungan antarkalimat yang satu dengan kalimat yang lain di dalam teks. Dalam menganalisis data, peneliti menggunakan teori Analisis Wacana Tarigan.

Adapun bagan alir penelitian ini sebagai berikut:

Bagan 1

Bagan Alir Data

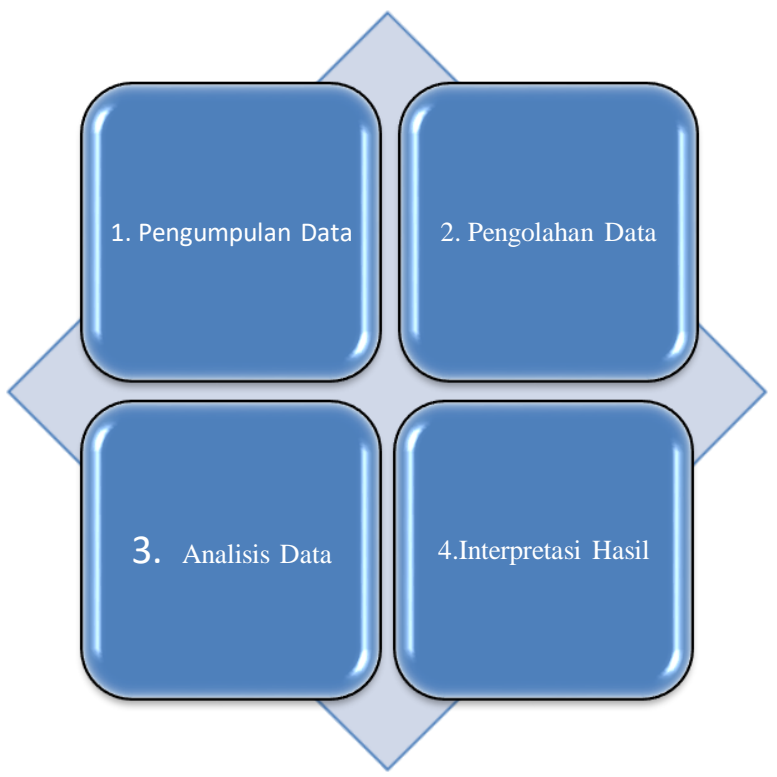

Lokasi penelitian ini adalah di Universitas Indraprasta PGRI di Jalan Nangka No.58c Tanjung Barat Jagakarsa Jakarta Selatan. Sumber data yang digunakan adalah esai mahasiswa pada mata kuliah Psikologi Sastra. Data penelitian ini adalah penggalan wacana dalam karangan yang diduga terdapat hubungan bentuk kohesi gramatikal di dalamnya. Hasil analisis data dalam penelitian ini disajikan dengan menggunakan metode penyajian informal. Dalam penyajian ini, kaidah-kaidah disampaikan dengan kata-kata biasa, kata-kata yang apabila dibaca dengan serta merta dapat langsung dipahami. Kaidah itu berupa prinsip-prinsip kesinambungan wacana yang terdapat dalam esai mahasiswa. Instrumen penelitian adalah peneliti sendiri sebagai instrumen kunci dan memahami unsur referensi, subtitusi, elipsis, dan konjungsi.

Fokus penelitian ini adalah piranti kohesi gramatikal dalam esai mahasiswa Universitas Indraprasta PGRI. Subfokus penelitian ini adalah Subtitusi, Referensi, Ellipsis, dan Konjungsi. 
Teknik pengumpulan dan penganalisian data, peneliti menempuh langkah-langkah atau teknik pencatat data dilakukan dengan beberapa langkah-langkah sebagai berikut: mencermati isi esai mahasiswa. Setelah itu, peneliti menganalisis kohesi gramatikal yang ada dalam esai mahasiswa kemudian merekapitulasi jumlah dan persentase data, dan memasukkan data ke dalam tabel kerja, terakhir menarik simpulan berdasarkan data penelitian.

Berpijak dari hal tersebut, dalam penelitian ini untuk mengecek keabsahan data, peneliti mengecek kembali data yang terkumpul dengan cara menganalisis esai mahasiswa yang menjadi sumber data penelitian. Hal ini bertujuan untuk menghindari adanya data yang belum tercatat dalam pencatatan pertama, peneliti menggunakan teknik triangulasi yang merupakan teknik pemeriksaan keabsahan data dengan cara memanfaatkan sesuatu yang lain terlepas dari data yang diambil adapun triangulasi yang digunakan adalah triangulasi data. Kegiatan ini dilakukan untuk keperluan pengecekan sebagai pembanding terhadap data yang telah ada. Data yang telah diambil kemudian dibandingkan dengan data dari hasil analisis kesalahan berbahasa pada penelitian lain

\section{Hasil dan Diskusi}

Data piranti kohesi gramatikal dalam esai mahasiswa Universitas Indraprasta PGRI Jakarta diteliti dari esai mahasiswa UNINDRA PGRI semester IV, yaitu kelas R4B sebanyak 30 mahasiswa. Dengan demikian esai yang diteliti sebanyak 30 esai. Mahasiswa ditugaskan untuk menulis esai dengan tema: (1) simbol dalam kebudayaan (2) Pendidikan karakter dalam karya Sastra, (3) Sastra Anak. Mahasiswa memilih satu tema lalu dikembangkan menjadi esai.

Hasil penelitian akan dijelaskan berdasarkan klasifikasi kohesi gramatikal yang terdiri dari referensi, subtitusi, ellipsis, dan konjungtif. Peneliti mengecek kembali data yang terkumpul dengan cara menganalisis esai mahasiswa yang menjadi sumber data penelitian, kemudian mencatat di dalam kartu data penelitian tentang kohesi gramatikal. Setelah melakukan pencatatan, kemudian peneliti mengklasifikasikan berdasarkan tipe-tipe kohesi gramatikal dalam esai mahasiswa.

Kohesi merupakan aspek formal bahasa dalam wacana (hubungan yang tampak pada bentuk). Kohesi merupakan tempat kalimat-kalimat yang disusun secara padu dan padat untuk menghasilkan tuturan (Tarigan 2009:93). Kohesi adalah hubungan antarkalimat di dalam sebuah wacana baik dalam skala gramatikal maupun skala leksikal tertentu.

Arifin, dkk (2015: 51) mengungkapkan bahwa ada dua jenis kohesi, yaitu kohesi gramatikal dan kohesi leksikal. Setiap kohesi mempunyai sifat relasi masing-masing, yang menunjukkan pertalian bentuk, pertalian referensi, ataupun pertalian makna.

Piranti kohesi gramatikal menurut Arifin, dkk (2015: 51) adalah kohesi gramatikal digunakan untuk menunjukkan adanya hubungan bentuk (bahasa) di antara kalimat pembangun wacana. Kohesi gramatikal terdiri atas referensi, substitusi, elipsis, dan relasi konjungtif. Pada penelitian ini ditemukan contoh kohesi gramatikal diuraikan sebagai berikut:

Referensi Ramlan dalam (Arifin, dkk., 2015: 60) menyebutkan bahwa referensi (pengacuan) menjadi bagian dari kohesi gramatikal yang berkaitan dengan penggunaan kata atau kelompok kata untuk mengacu pada kata, kelompok kata, atau satuan gramatikal lainnya. Berikut ini data yang ditemukan pada esai mahasiswa.

a. Masyarakat sangat tersulut emosinya, seperti pelaku para demonstran yang membakar kendaraan.(P1,

K5) Fenomena tersebut dapat menjadi represenasi melemahnya karakter bangsa ini.(PI,K6) Frase

fenomena tersebut merupakan referensi anafora karena menjelaskan kalimat sebelumnya.

b. Dunia anak yang penuh dengan imajinasi dan impian harus diarahkan pada pola pikir kritis.(P2,K2) Ini bisa diperoleh dengan cara anak membiasakan diri dengan membaca (P2, K4) Kata Ini merupakan referensi katafora karena menjelaskan kalimat berikutnya.

c. Setelah itu, calon pengantin pria ini menyerahkan beberapa bingkisan seserahan yang berjumlah ganjil, disertai maksud dan tujuannya; menyatakan kemantapan hatinya untuk menikahi wanita pujaannya. (P7,K1) Kalimat tersebut terdapat referensi anafora yaitu -nya pada tujuannya, hatinya, pujaannya. Termasuk referensi anafora karena -nya menjelaskan klausa sebelumnya.

d. Tidak terbatasnya imajinasi bisa jadi sangat dimungkinkan, namun beberapa prasyarat di atas menjadi rambu-rambu materi karya sastra apa yang aman dikonsumsi oleh anak-anak. $(\mathrm{P} 7, \mathrm{~K} 3)$ Kalimat tersebut terdapat referensi katafora yaitu kata terbatasnya. Kata terbatasnya 
menjelaskan kata setelahnya, yaitu kata imajinasi.

e. Ahli sastra menyatakan salah satu fungsi sastra adalah sebagai media kataris atau pembersih jiwa dan pikiran bagi penulis maupun pembacanya. (P5, K2) Kalimat tersebut terdapat referensi anafora yaitu kata Pembacanya. Kata Pembacanya menjelaskan kata sebelumnya, yaitu pembaca karya sastra.

f. Jika mereka lebih banyak diajarkan atau dibiasakan untuk gemar membaca, sopan, santun, dan perilaku positif lainnya, setelah besar hal-hal baik itu pasti akan terbiasa. Kalimat tersebut terdapat Referensi Eksofora Pronomina Persona, sebab kata mereka merupakan pronomina persona orang ketiga jamak.

Konjungtor menurut kridalaksana dalam (Arifin et al., 2015) adalah konjungtor (kata sambung) adalah bentuk atau satuan kebahasaan yang berfungsi untuk menyambung, merangkai, atau menghubungkan kata dengan kata, frasa dengan frasa, klausa dengan klausa, kalimat dengan kalimat dan seterusnya. Berikut ini data yang ditemukan pada esai mahasiswa.

a. Sastra anak dipandang sangat penting dan berpengaruh pada pola pikir anak (P1, K1) dan merupakan konjungsi koordinatif penambahan.

b. Ada delapan urutan ritual dalam upacara panggih yaitu: 1...(P2, K3) Yaitu merupakan konjungsi subordinatif perincian, yaitu merincikan urutan ritual upacara panggih.

c. Baik dari orang dewasa hingga anak-anak tidak dapat menolak atau menentang perkembangan teknologi ini. (P1, K2) Kalimat tersebut memiliki dua konjungsi, yaitu Kata Hingga dan atau. Kata Hingga merupakan konjungsi subordinatif hasil. Atau merupakan konjungsi koordinatif pemilihan

d. Keberhasilan kegiatan membaca tidak mungkin dapat dicapai apabila anak-anak tidak tertarik pada bacaan yang mereka baca karena tidak memberikan pengalaman yang menyenangkan.(P5, K4) Kalimat tersebut terdapat 3 konjungsi, yaitu apabila, yang, karena. Kata apabila merupakan konjungsi subordinatif syarat. Kata yang merupakan konjungsi subordinatif atributif. Kata karena merupakan konjungsi subordinatif sebab.

e. Adat saat menikah begitu menarik membuat masih banyak dilakukan hingga sekarang. (P6,K1) Kalimat tersebut terdapat konjungsi subordinatif hasil yaitu kata hingga.

f. Namun, kenyataan secara luas tetap memperlihatkan studi atau pendalaman terhadap peran atau fungsi sastra anak dalam masyarakat masih sangat minim (P5, K1) Konjungsi antarkalimat pertentangan, yaitu kata namun.

g. Ritual itu tetap ada, tapi tidak untuk konsumsi umum, lebih kepada salah satu rangkaian mutih sebelum penikahan. (P3, K3) Konjungsi Konjungsi Koordinatif Sasaran, yaitu untuk, dan Konjungsi Subordinatif Waktu, yaitu sebelum.

Selanjutnya, substitusi menurut Kridalaksana dalam (Arifin et al., 2015) adalah proses dan hasil penggantian unsur bahasa oleh unsur lain dalam satuan yang lebih besar. Penggantian itu dilakukan untuk memperoleh unsur pembeda atau untuk menjelaskan struktur tertentu. Berikut ini data yang ditemukan pada esai mahasiswa ....

a. "Walaupun ini lagu Jawa, tapi hampir semua orang tahu lagu ini.(P1, K3) Kata Ini merupakan subtitusi nomina, yaitu menggantikan frase nomina lagu jawa.

b. "Temanten anyar" artinya penganten baru, ada juga yang mengartikan sebagai raja-raja Jawa yang baru memeluk agama Islam. (P4, K3) Kata juga merupakan Substitusi Nomina, yaitu menggantikan frase nomina temanen anyar.

c. Pada malam hari sebelum akad nikah terdapat acara midodareni yaitu pengantin wanita mulai

dirias seperti memotong rambut, membentuk alis, dan wanita tersebut tidak diperbolehkan keluar dari rumah (dipingit). (P3, K7) Kata tersebut merupakan subtitusi demonstrative karena menggantikan frase pengantin wanita.

d. Pendidikan karakter adalah suatu sistem penawaran nilai-nilai karakter kepada warga sekolah (warga masyarakat) yang mencakupi komponen pengetahuan, kesadaran atau kemauan, dan tindakan untuk melaksanakan nilai-nilai tersebut, baik terhadap Tuhan Yang Maha Esa, diri sendiri, lingkungan, maupun kebangsaan. $(\mathrm{P} 1, \mathrm{~K} 1)$. Kata tersebut merupakan subtitusi demonstratif karena menggantikan frase nilai pendidikan karakter.

e. Kerja keras yang dilakukan oleh Karang untuk menemukan cara berkomunikasi dengan Melati, mandiri dalam berusaha mendapatkan kesuksesannya sendiri, demokrasi dalam hal ini kebebasan dalam berfikir. $(\mathrm{P} 5, \mathrm{~K} 3)$. Kalimat tersebut merupakan subtitusi nomina, sebab .... dalam hal ini .... menggantikan kalimat 
kerja keras yang dilakukan oleh Karang untuk menemukan cara berkomunikasi dengan Melati, mandiri dalam berusaha mendapatkan kesuksesannya sendiri....

f. Novel ini dapat dijadikan media pembelajaran dalam pendidikan karakter dengan cara pembaca meresapi nilai-nilai kebaikan yang terkandung di dalamnya. Kata ini merupakan subtitusi demonstratif karena kata ini menunjukkan sebuah novel dengan judul Moga Bunda Disayang Alloh karya Tere Liye.

Sedangkan, pelesapan (Elipsis) menurut Kridalaksana dalam (Arifin et al., 2015) \ pelesapan atau penghilangan (elipsis) adalah proses melesapkan bagian tertentu (kata atau satuan kebahasaan lainnya) di dalam kalimat. Bentuk atau unsur yang dilesapkan itu dapat diperkirakan wujudnya, melalui konteks bahasa atau konteks luar bahasa. Berikut ini data yang ditemukan pada esai mahasiswa ....

a. Ada versi wayang yang dimainkan oleh orang dengan memakai kostum, [ ] dikenal orang sebagai wayang orang, dan ada wayang [ ]berupa sekumpulan boneka [ ] dimainkan oleh seorang dalang (P5, K6) Yang merupakan ellipsis, [yang] dikenal orang sebagai wayang orang.

b. Perkembangan bahasa, [ ]kognitif, [ ]kepribadian dan [ ]sosial (P4, K6) [ ] kognitif, [ ]kepribadian dan [ ]sosial, ada yang lesap yaitu kata perkembangan.

c. Kerja keras yang dilakukan oleh Karang untuk menemukan cara berkomunikasi dengan Melati, mandiri dalam berusaha mendapatkan kesuksesannya sendiri, demokrasi dalam hal ini kebebasan[ ]berfikir. (P5, K3) Elipsis/Pelesapan dalam kalimat tersebut yaitu demokrasi dalam hal ini kebebasan [dalam] berfikir.

d. Adat saat menikah begitu menarik [ ]masih banyak dilakukan hingga sekarang. (P6, K1) Elipsis/Pelesapan dalam kalimat tersebut yaitu adat saat menikah begitu menarik [membuat] masih banyak dilakukan ....

e. Kerja keras yang dilakukan oleh Karang untuk menemukan cara berkomunikasi dengan Melati, mandiri dalam berusaha mendapatkan kesuksesannya sendiri, demokrasi dalam hal ini kebebasan dalam berfikir. (P5, K3). Elipsis/Pelesapan dalam kalimat tersebut yaitu ...., demokrasi dalam hal ini kebebasan [dalam] berfikir.

f. Orang Ngawi, Jawa Timur patut berbangga karna memiliki adat dan kebudayaan yang sangat banyak dan beraneka ragam. Mereka harus tetap melestarikan kebudayaannya agar tetap lestari dan harus dilaksanakan oleh anak dan cucu mereka untuk ke depannya. (P 8, K 1 dan2)

Elipsis/Pelesapan dalam kalimat tersebut yaitu Mereka harus tetap melestarikan kebudayaannya agar [tetap] lestari dan harus dilaksanakan.

Tabel 1.

Instrumen Temuan Data Penelitian Kohesi Gramatikal dalam Esai Mahasiswa Universitas Indraprasta PGRI Jakarta

\begin{tabular}{|c|c|c|c|}
\hline NO & KOHESI GRAMATIKAL & TEMUAN & PERSENTASE \\
\hline 1 & REFERENSI & 46 & $24,1 \%$ \\
\hline 2 & SUBTITUSI & 5 & $2.6 \%$ \\
\hline 3 & ELIPSIS & 8 & $4.2 \%$ \\
\hline 4 & RELASI KONJUNGTIF & 132 & $69.1 \%$ \\
\hline & JUMLAH & 191 & $100 \%$ \\
\hline
\end{tabular}

Menurut (Wiana, 2011) analisis kajian analisis kohesi juga dapat dilakukan dengan teori Lingusitik Fungsional Sistemik, dengan mengkaji opini dalam lima objek wacana yang ia teliti. Aspek yang diteliti adalah jenis alat kohesi gramatikal yaitu meliputi; perujuk ellipsis/substitusi, dan konjungsi. 
Pada asek perujuk terdiri atas kata ganti (pronominal), penunjuk dan perbandingan yang terdapat ada kelima wacana opini yang ia teliti. Namun, bentuk yang mendominasi pada kelima wacana yang dianalisis adalah alat perujuk dan konjungsi.

Sedangkan dari penelitian lainnya (Hanafiah, 2015) pada aspek kohesi gramatikal berupa pelesapan atau ellipsis ditemukan sebagaik 6 paragraf yang mengandung pelesaan kausal. Dengan demikian, hal ini menyebabkan bahwa pelesapan kausal dapat ditemukan dalam wacana tulis yang bersifat informal. Aspek berikutnya yang ditemukan adalah konjungsi, yang hampir disetiap paragraf memiliki konjungsi dan ditemukan hanya satu paragraf yang tidak memiliki konjungsi. Dalam hal ini simpulannya adalah jenis konjungsi yang muncul didominasi oleh konjungsi kausal. Namun demikian, ada juga konjungsi adiftif atau penambahan, pilihan, koordinatif dan adversatif.

Hasil penelitian ini menunjukkan piranti kohesi gramatikal yang terdapat dalam esai mahasiswa yaitu; referensi 46 dengan persentase $24,1 \%$, subsitusi 5 dengan persentase 2,6\%, ellipsis 8 dengan persentase $4,2 \%$ dan relasi konjungtif 132 dengan persentase $69,1 \%$. Berdasarkan hal tersebut dari 30 esai karangan mahasiswa terdapat 191 jumlah piranti kohesi gramatikal yang terkandung didalamnya. Piranti kohesi gramatikal yang ditemukan adalah Referensi anafora dan katafora, subtitusi, ellipsis, dan relasi konjungsi subordinatif atributif, konjungsi koordinatif penambahan, konjungsi koordinatif pemilihan, dan konjungsi Subordinatif Perincian.

Sebagian besar kohesi gramatikal yang ditemukan adalah jenis konjungsi, yaitu sebanyak 132 konjungsi. Hal ini terjadi karena konjungsi sebagai penghubung dapat ditempatkan secara intrakalimat maupun antarkalimat. Jenis referensi yang ditemukan adalah referensi anafora dan referensi katafora. Jenis konjungsi yang ditemukan yaitu (1) konjungsi subordinatif atributif, (2) konjungsi koordinatif penambahan, (3) konjungsi koordinatif pemilihan, dan (4) konjungsi subordinatif perincian, (5) konjungsi pertentangan antarkalimat. Jenis subtitusi yang ditemukan yaitu subtitusi nomina dan subtitusi demonstratif.

\section{Simpulan}

Hasil penelitian ini menunjukkan piranti kohesil gramatikalnya yaitu; referensi 46 dengan persentase $24,1 \%$, subsitusi 5 dengan persentase 2,6\%, elipsis 8 dengan persentase $4,2 \%$ dan relasi konjungtif 132 dengan persentase 69,1\% . Piranti kohesi gramatikal yang ditemukan adalah Referensi anafora dan katafora, subtitusi, ellipsis, dan relasi konjungsi Subordinatif Atributif , Konjungsi Koordinatif Penambahan, Konjungsi Koordinatif pemilihan, dan Konjungsi Subordinatif Perincian. Dari 30 esai karangan mahasiswa terdapat 191 jumlah piranti kohesi gramatikal yang terkandung didalamnya. Dengan demikian dapat disimpulkan dalam esai karangan mahasiswa, sebagian besar kohesi gramatikal yang digunakan adalah konjungsi atau kata hubung, karena kata hubung dapat ditempatkan secara intrakalimat ataupun antarkalimat.

\section{Ucapan Terima Kasih}

Pada kesempatan ini kami mengucapkan terima kasih kepada semua pihak yang telah memberikan bantuan dan dorongan dalam melaksanakan penelitian ini, terutama kepada LPPM Universitas Indraprasta PGRI, seluruh staf jajaran civitas akademika baik dosen dan mahasiswa yang terlibat dalam penelitian ini. Tim penyusun dan editor yang telah membantu menyelesaikan hasil produk penelitian. 


\section{Daftar Rujukan}

Arifin, E.Z., dkk. Wacana Transaksional dan Interaksional dalam Bahasa Indonesia. Jakarta: Pustaka Mandiri. 2015.

Arifin, E.Z., dkk. Teori dan Kajian Wacana Bahasa Indonesia. Jakarta: Pustaka Mandiri. 2012.

Hanafiah, W. Analisis Kohesi dan Koherensi pada Wacana Buletin Jumat. Epigram, 11(2). 2015

Helaluddin, H. Analisis Struktur Esai Mahasiswa Pada Mata Kuliah Bahasa Indonesia di IAIN Sultan Maulana Hasanuddin Banten. Jurnal Bindo Sastra, 1(1), 15-23. 2017

Khuzaemah, E., \& Herawati, L. Pembelajaran Menulis Esai Menggunakan Model Cooperative Integrated Reading and Composition (CIRC) Berbasis Life Skills. Indonesian Language Education and Literature, 2(2), 148-162. 2017

Tarigan, Henry Guntur. Pengajaran Wacana. Bandung: Angkasa.2009

Wiana, D. Analisis kohesi pada rubrik opini surat kabar Analisa. Jurnal Ilmiah Abdi Ilmu, 4(2), 653-659. 2011 